\title{
The unbundling regime for electricity utilities in the EU: A case of legislative and regulatory capture?
}

\author{
SILVESTER VAN KOTEN AND ANDREAS ORTMANN, CERGE-EI
}

\section{Summary}

$\mathrm{T}$ he European electricity market is undergoing major changes. Prompted by EU (European Union) legislation, the $\mathrm{EU}$ member states are restructuring their electricity industry to allow for more competition, which is widely believed to be welfare-enhancing. A major complication is that, at the outset, the electricity markets were almost completely controlled by large, Vertically Integrated Utilities (VIUs) that used to be regulated state monopolies. These VIUs typically still own almost all generators, as well as the transmission and/or distribution networks. Such an ownership pattern is believed to be an obstacle to free competition.

To prevent VIUs from using their influence to reduce competition, the EU has required its member states to unbundle (separate) their generation and network activities. Many members, however, have been slow in implementing these directives and many have chosen a weaker (but permitted) form of unbundling. These developments, and the fact that weaker forms of unbundling are allowed at all, are widely believed to be welfare-reducing. These observations suggest that the pertinent political, legislative, and regulatory processes might have been unduly influenced.

We investigated whether among the old EU member states, countries that are more corrupt, as measured by the CPI (Corruption Perception Index, a well- established corruption indicator published by Transparency International), are more likely to apply weaker forms of unbundling. Somewhat surprisingly, we do not obtain a similar finding for the EU member states that acceded in 2004. We provide a conjecture for this observation.

\section{What is known?}

Arguably, the largest obstacle both to creating a single market in energy and allowing more competition is the dominance of large, formerly regulated VIUs that were typically state monopolies. The fact that VIUs own both generators and transmission/distribution networks is especially problematic as it allows VIUs to use their network ownership to increase their profits and hinder competition.

For example, VIUs can cross-subsidize their generation activities and recover their generation losses with high transmission fees. Apart from blunt refusal, VIUs have several additional tactics available to hinder the access of competing generators to the network such as imposing discriminatory requirements or charging unreasonably high access and service fees. Furthermore, VIUs have little incentive to invest in new transmission capacity as more transmission capacity makes it more likely that generators from neighboring countries or distant areas can compete with the VIU-owned generators. This puts independent generators at a disadvantage and thereby decreases competition.
To prevent VIUs from using their control over the networks to reduce competition, the EU requires member states to unbundle (separate) their transmission and distribution networks from generation. The EU distinguishes five types of such unbundling:

o) Unified ownership requires no unbundling: both network and generation activities continue to be owned and managed by the same company.

I) Accounting unbundling is the least drastic form of unbundling: separate accounts must be kept for network and generation activities to prevent cross subsidization.

2) Functional unbundling (also called management unbundling) requires, in addition to keeping separate accounts, that the operational activities and management are separated for transmission and generation activities.

3) Legal unbundling requires that transmission and generation be put in separate legal entities.

4) Ownership unbundling is the most drastic form of unbundling. Generation and transmission have to be owned by independent entities. These entities are not allowed to hold shares in both activities.

Interestingly, the EU allows its member states the choice of an unbundling regime (legal or ownership) and the pace of implementation (quick or slow), although there seems to be wide agreement that the quick implementation of ownership unbundling 
would be welfare-enhancing. Legal unbundling leaves intact the incentives for curbing competition. Not surprisingly, in many countries VIUs opposed ownership unbundling in favor of legal unbundling. It is therefore an interesting question (to which our results provide a suggestive answer) whether VIUs were able to manipulate the legislative and regulatory process in favor of the weaker form of unbundling, and whether these manipulations were a function of the integrity of legislative and regulatory processes.

\section{Example 1: questionable strategies in the Netherlands}

A recent scandal in the Netherlands illustrates one questionable strategy. In January 2006, it became known that energy companies Nuon, Eneco, Essent, and Delta had secretly promised, contingent on the Netherlands' government deciding against the ownership unbundling of the distribution network, a "success fee" of I.7 million Euro to IMSA, an environmentally-oriented consultancy company that presents itself as independent and respectable. IMSA had forcefully argued against ownership unbundling of energy networks in the Dutch media and in an IMSA consultancy report. This example is suggestive of the possible questionable strategies energy companies can use to prevent unbundling and the value of weaker unbundling for energy companies.

Tables ra and ib document the considerable variation in the unbundling regimes implemented in EU member states, and the distribution of regimes over time, both for the old (EU-I 5 ) and the new member states that acceded the EU in 2004 (NMS-IO).

The fact that legal unbundling is the modal choice for the NMS-Io and the EUI 5 countries in 200 I-2 (and a close contender even in 2003-5) is one indication that VIUs may be able to exert influence over the transmission company. We therefore conjecture that part of the variation in the unbundling regime choice and the

Table 1a: Unbundling regimes in the (old) EU-15 member states.

\begin{tabular}{|c|c|c|c|c|c|c|}
\hline \multicolumn{7}{|c|}{ EU-15 countries } \\
\hline Unbundling regime & 2001 & 2002 & 2003 & 2004 & 2005 & 2006 \\
\hline 0) None & 0 & 0 & 0 & 0 & 0 & 0 \\
\hline 1) Account & 0 & 0 & $\begin{array}{c}1 \\
\text { (L) }\end{array}$ & 0 & 0 & 0 \\
\hline 2) Functional & $\begin{array}{c}3 \\
(D, F, G R)\end{array}$ & $\stackrel{2}{2}$ & $\begin{array}{c}1 \\
\text { (F) }\end{array}$ & $\begin{array}{c}1 \\
\text { (L) }\end{array}$ & 0 & 0 \\
\hline 3) Legal & $\begin{array}{c}8 \\
(A, B, D K, E, \\
I, I R L, N L, P)\end{array}$ & $\begin{array}{c}5 \\
(A, B, D, \\
D K, P)\end{array}$ & $\begin{array}{c}4 \\
(A, B, D, \\
\text { DK) }\end{array}$ & $\begin{array}{c}7 \\
(\mathrm{~A}, \mathrm{~B}, \mathrm{D}, \mathrm{DK}, \\
\mathrm{F}, \mathrm{GR}, \mathrm{IRL})\end{array}$ & $\begin{array}{c}7 \\
(A, B, D, F, \\
G R, I R L, L)\end{array}$ & $\begin{array}{c}7 \\
(\mathrm{~A}, \mathrm{~B}, \mathrm{D}, \mathrm{F} \\
\mathrm{GR}, \mathrm{IRL}, \mathrm{L})\end{array}$ \\
\hline 4) Ownership & $\begin{array}{c}3 \\
(\mathrm{FIN}, \mathrm{S}, \mathrm{UK})\end{array}$ & $\begin{array}{c}5 \\
(\mathrm{E}, \mathrm{FIN}, \mathrm{NL}, \\
\mathrm{S}, \mathrm{UK})\end{array}$ & $\begin{array}{c}6 \\
(E, F I N, \\
N L, P, S, U K)\end{array}$ & $\begin{array}{c}7 \\
(E, F I N, I, \\
\text { NL, P, S, UK) }\end{array}$ & $\begin{array}{c}8 \\
\text { (DK, E, FIN, I, } \\
\text { NL, P, S, UK) }\end{array}$ & $\begin{array}{c}8 \\
(\mathrm{DK}, \mathrm{E}, \mathrm{FIN}, \mathrm{I}, \\
\mathrm{NL}, \mathrm{P}, \mathrm{S}, \mathrm{UK})\end{array}$ \\
\hline
\end{tabular}

Table 1b: Unbundling regimes in the (new) NMS-10.

\begin{tabular}{|c|c|c|c|c|c|c|}
\hline \multicolumn{7}{|c|}{ NMS-10 } \\
\hline Unbundling regime & 2001 & 2002 & 2003 & 2004 & 2005 & 2006 \\
\hline 0) None & & 0 & 0 & 0 & 0 & 0 \\
\hline 1) Account & & $\begin{array}{c}1 \\
(H)\end{array}$ & $\begin{array}{c}2 \\
(\mathrm{EST}, \mathrm{H})\end{array}$ & $\begin{array}{c}1 \\
\text { (LV) }\end{array}$ & 0 & 0 \\
\hline 2) Functional & & $\begin{array}{c}2 \\
\text { (CY, EST) }\end{array}$ & $\begin{array}{c}2 \\
(C Y, P L)\end{array}$ & $\begin{array}{c}1 \\
\text { (CY) }\end{array}$ & $\begin{array}{c}1 \\
\text { (CY) }\end{array}$ & 0 \\
\hline 3) Legal & & $\begin{array}{c}6 \\
\text { (CZ, LT, LV, } \\
\text { PL, SK, SLO) }\end{array}$ & $\begin{array}{c}5 \\
\text { (CZ, LT, LV, } \\
\text { SK, SLO) }\end{array}$ & $\begin{array}{c}7 \\
\text { (CZ, EST, H, } \\
\text { LT, PL, SK, SLO) }\end{array}$ & $\begin{array}{c}4 \\
\text { (EST, LV, PL, } \\
\text { SK) }\end{array}$ & $\begin{array}{c}5 \\
\text { (CY, EST, LV, } \\
\text { PL, H) }\end{array}$ \\
\hline 4) Ownership & & 0 & 0 & 0 & $\begin{array}{c}4 \\
\text { (CZ, H, LT, } \\
\text { SLO) }\end{array}$ & $\begin{array}{c}4 \\
\text { (CZ, LT, SLO, } \\
\text { SK) }\end{array}$ \\
\hline
\end{tabular}

speed of implementation can be explained by the activities of VIUs to influence the outcome. These activities may be legal (e.g., transparent lobbying activities) or may include questionable (and possibly illegal) strategies such as under-the-table payments to allegedly independent consultants to affect public opinion and the legislative and regulatory process. Of course, it may also be possible that outright bribes were paid.

The effect of such questionable activities depends on the integrity of legislative and regulatory processes. Data that directly measure the integrity of such processes do not exist. We therefore use the CPI as a proxy. The CPI is a widely used and wellestablished corruption assessment instrument that reflects the (perception of) the corruption in a country; it assigns countries a score between I (very corrupt) and Io (hardly corrupt at all). The score is based on a number (up to I 8 ) of sources, not all of them just about perception. In some sense the name of the CPI has become an anachronism. The CPI of 2006 was based on $\mathrm{I} 2$ indicators from 9 independent institutions.
We can now formulate our conjecture as follows: Countries with higher CPI scores (less corruption) have more complete unbundling regimes.

\section{Empirical findings}

To test our hypothesis, we ran (ordered logit) regressions with transmission unbundling regime and quality of implementation, respectively, as the dependent variables and $C P I$ and various controlling variables as regressors.

For the EU-I 5 countries, Model I shows that the effect of the CPI is highly significant and positive. This supports our hypothesis: The less corrupt of the EU-I 5 countries (a high CPI score) tend to implement more rigorous transmission unbundling. The effect of the CPI is highly significant and robust. We checked the effect of the CPI using alternative methods of data analysis and performing various additional tests: the effect of the CPI remains highly significant in all settings.

Interestingly, the effect of the CPI on the NMS-Io (model 2) is opposite to the effect in EU-I 5 countries (model I): more cor- 
Table 2: Regression output

CPI
TimeTrend
GDP_pc (in thousands)
GDP (in millions)
HHI_med
Netlmport_Gen
N
** * Significant at the $1 \%$ confidence level
* * Significant at the $5 \%$ confidence level
* Significant at the $10 \%$ confidence level
() Robust standard errors within parentheses

rupt countries in the NMS-Io sample tend to implement more rigorous transmission unbundling. A possible explanation is that the reverse CPI effect is spurious; the effect is significant but not as robust as the CPI effect we found for EU-I 5 countries and effectively it is very small. Moreover, we have reasons to suspect that the transmission unbundling regime has not always been reported accurately for the NMS-Io. For example, in four out of the eight countries in our NMS-Io sample the unbundling regime becomes less rigorous in time over certain periods. The case of Latvia (see Example 2) gives an illustrative example.

It seems likely that the occurrence of misreporting is related to the level of corruption in the NMS-Io. After all, in the pre-accession stage the European Commission has exerted strong pressure on the NMS-Io to show clear signs of reform to be eligible for EU membership in 2004. Compliance with the unbundling requirements is a step towards creating a liberal market economy and a way for an accession country to signal its commitment for reform to the EU. Especially for very corrupt countries such formal compliance, without actually following up on it, is a cheap signal relative to actually curbing anticompetitive practices and governmental corruption. This might explain why more corrupt countries choose (at least formally) more rigorous unbundling. As the rationale for misreporting was eliminated once the NMS-Io had acceded to the EU in 2004, we expect to observe variance in the effect of the CPI over time. Indeed, additional analysis showed that the effect of the CPI differs significantly over time ( $p<0.0003$ ); the negative effect of the CPI on the unbundling regime was most pronounced in the period 2002-2004, but less so in 2005 and 2006.

\section{Conclusions and policy recommendations}

For the EU-I 5 countries, we found a significant and robust effect of a well-established corruption measure on the realized unbundling regime: countries that are more corrupt are more likely to have chosen weaker unbundling regimes than seems desirable. The fact that politicians who are likely to be more corrupt allow less unbundling is an indication that less unbundling is indeed a way to grant VIUs higher rents. It also suggests that the choice EU law provides - a choice not suggested by economic theory - might be the result of a legislative process that has been compromised through questionable means of persuasion. as Legal. This report allowed Latvia to fulfill the accession criteria in this respect. However the unbundling regime in Latvia was reported in the DG Tren reports on 2004 (published after accession) as Accounting, meaning that Latvia in reality failed the accession criteria in this respect. In addition, the unbundling regime in Latvia in 2002 and 2003 are now being reported by the Latvian regulator as Accounting, which indicates that the reported Legal unbundling in 2002 and 2003 were misleading reports. Interestingly, the CPI identifies Latvia as the most corrupt country in $200 \mathrm{I}$ and 2002 in our sample of EU-25 countries, and one of the smallest economies in our sample of the NMS-Io (its GDP is about $20 \%$ of the average). Latvia, with its misleading reports, its small size and high corruption, is a prototypical example for the relationships we found between the variables in our regression for the NMS-Io.

\section{In light of our results, we believe that the EU should require owner- ship unbundling of transmission and consider additional measures to curtail the economic and political power of VIUs.}

Our result adds empirical evidence to a literature that casts doubt on the wisdom of allowing a weak unbundling regime that facilitates the continued existence of large utilities that are effectively still integrated. In addition, our result suggests that VIUs in countries that are more corrupt might use - apart from legal lobbying channels and questionable (but not illegal) practices - illegal means to further their interests. In light of our results, we believe that the EU should require ownership unbundling of transmission and consider nomic and political power of VIUs. additional measures to curtail the eco- 
The analysis that focused only on the NMS-Io shows a weaker but statistically significant effect in the opposite direction. We conjecture that some countries in the NMS-Io sample reported early adoption of formal EU requirements as a cheap means to increase their chances to be judged eligible for accession to the EU. This strategy should be especially attractive for corrupt countries, for which it is costly to implement other EU requirements such as curbing anticompetitive practices and gov- ernmental corruption. The result reminds us that there is an important difference between laws and regulations and their effective implementation.

The research is presented in more detail by the same authors under the same title in the academic journal "Energy Economics", and is available at http://dx.doi.org/I0.I0I6/j.eneco.2008.07.002.

\section{Principal Investigators:}

Silvester van Koten, PhDr., Drs., M.A

Silvester.VanKoten@cerge-ei.cz

Junior Researcher at CERGE-EI
A. Ortmann, Doc., Ph.D.

Andreas.Ortmann@cerge-ei.cz

Professor and Senior Researcher at CERGE-EI

The opinions findings, conclusions or recomendations expressed herein are those of the author(s) and do not necesarily reflect the views of the trustees, officers, or other staff members of the CERGE-EI or supporting institutions. (C) CERGE-EI, 2008

CERGE-EI is a joint workplace of the Center for Economic Research and Graduate Education at the Charles University in Prague and the Economics Institute of the Academy of Sciences of the Czech Republic. CERGE-EI provides an American-style Ph.D. program in economics and conducts state-of-the-art research in theoretical and policy-related economics, with a particular emphasis on the transition to free markets and European integration. The Ph.D. degree from CERGE-EI is fully recognized both in the Czech Republic and in the United States. 